\title{
Caracterização do mercado consumidor de "água aromatizada": hábitos e motivações para o consumo
}

\author{
Characterization of the consumer market of "flavored water": \\ habits and motivations for the consumption
}

\author{
Érika ENDO ${ }^{1}$, Michele Corrêa BERTOLDI ${ }^{1}$, Neuma Maria de Souza PINHEIRO ${ }^{1}$, \\ Aline Cristina ARRUDA ${ }^{1}$, Valéria Paula Rodrigues MINIM ${ }^{1 *}$
}

\section{Resumo}

O produto preparado líquido aromatizado, comercialmente conhecido como "água aromatizada" e recém-lançado no mercado brasileiro, é vendido com o apelo de saúde e inovação. No entanto, por se tratar de um produto pouco familiar aos hábitos de consumo da população brasileira, as motivações para o seu consumo ainda são desconhecidas. Diante deste contexto, o presente estudo teve por objetivo avaliar o perfil dos consumidores da cidade mineira de Juiz de Fora quanto ao produto, por meio de uma pesquisa de mercado realizada em junho de 2007. Para o levantamento dos dados, utilizou-se uma pesquisa descritiva direta e estruturada (survey) com 303 consumidores, por meio da aplicação de questionários estruturados. A faixa etária predominante (40,3\%) situou-se entre 20 e 30 anos, sendo a maioria do sexo feminino (65\%), com elevada escolaridade e renda familiar entre 1 e 6 salários mínimos (52,8\%). Dos indivíduos entrevistados, 37\% disseram que consumiram o produto motivados principalmente pelo fator novidade. Destes, 20,5\% confundiram o produto com refrigerantes de baixa gaseificação. A maioria dos respondentes demonstrou desconhecer o produto, fato que pode estar relacionado a falta de divulgação nos estabelecimentos comerciais e pelas empresas através da mídia local.

Palavras-chave: pesquisa de mercado; água aromatizada; bebidas; perfil do consumidor.

\begin{abstract}
The flavored drink commercially known as "flavored water" and recently launched in the Brazilian market is sold with health and innovation appeal. However, since it is not very familiar product to the habits of consumption of the Brazilian population, the motivation for its consumption is still unknown. The present study evaluated the behavior patterns of 303 consumers of the city of Juiz de Fora (MG), Brazil, towards the product through a market survey conducted in June 2007. A direct, descriptive, and structured survey was carried out using a structured questionnaire. The majority of the respondents (40.3\%) were within the age group between 20 and 30 years old and were high educated females (65.0\%) with family income between 1 and 6 minimum wages (52.8\%). The results indicate that $37 \%$ of the interviewees stated product stated that the novelty aspect of the product motivated its consumption. Among the interviewers, $20.5 \%$ mistook the studied product with soft drinks with low gasification rate. Most of the interviewees did not know the product, which can be a result of a lack of popularity of the product in commercial establishments and in companies due to poor marketing.

Keywords: market survey; flavored water; beverages; consumer profile.
\end{abstract}

\section{Introdução}

Nas últimas décadas, a preocupação com a saúde está cada vez mais visível no comportamento da população. A busca pela qualidade de vida se estende aos cuidados com a alimentação, caracterizada por uma crescente demanda por produtos saudáveis e com características nutricionais e sensoriais próximas dos alimentos in natura. Baseada nisto, a indústria alimentícia está cada vez mais atenta aos desejos do consumidor e investe na formulação e produção de novos produtos, concentrando seus esforços na área de marketing no apelo à vida saudável (ÁGUA \& VIDA, 2007a; WANSINK, 2007; ECONOMIA \& DESENVOLVIMENTO, 2005).

É neste contexto que se verifica o aumento do consumo de bebidas não alcoólicas e não carbonatadas, tais como sucos (prontos, concentrados, entre outros), chás e águas. Esta última categoria, apesar da simplicidade do sabor, demonstra um surpreendente mercado consumidor, com o volume consumido pelos brasileiros, no ano de 2006, girando em torno de 6,2 bilhões de litros (ÁGUA \& VIDA, 2007a).

Se antes a água mineral era vista como símbolo de status, cuja aquisição se restringia aos indivíduos de maior poder aquisitivo, hoje é vista como necessidade, constituindo parte dos gastos do orçamento doméstico de muitas famílias brasileiras. Segundo a ABINAM (Associação Brasileira da Indústria de Águas Minerais), a produção nacional de água mineral saltou de 1,5 bilhão de litros em 1995 para 5,6 bilhões em 2005, fato associado ao aumento do consumo doméstico, do turismo interno (consumo

Recebido para publicação em 2/10/2007

Aceito para publicação em 3/1/2009 (002896)

${ }^{1}$ Departamento de Tecnologia de Alimentos, Universidade Federal de Viçosa - UFV, Campus Universitário, CEP 36570-000, Viçosa - MG, Brasil,

E-mail:erikaendobr@yahoo.com.br; mibertoldi@yahoo.com.br; neumapinheiro@hotmail.com; acarrudaufv@yahoo.com.br; vprm@ufv.br

${ }^{*}$ A quem a correspondência deve ser enviada 
durante as viagens) e à substituição do refrigerante pelo produto em questão, uma escolha que está de acordo com a crescente cultura do bem-estar (ÁGUA \& VIDA, 2007a; ECONOMIA \& DESENVOLVIMENTO, 2005; WEINBERG, 2007).

Baseadas na boa perspectiva e com o intuito de gerar uma maior diferenciação, empresas vêm investindo em produtos à base de água através da incorporação de aroma, vitaminas e/ou sais minerais, sendo, por este motivo, conhecidos nos Estados Unidos e na Europa como "águas com valor agregado". Estes produtos apresentam mercado promissor, visto que em 2005 suas vendas no mercado norte-americano aumentaram mais de $200 \%$, movimentando cerca de 455 milhões de dólares e correspondendo a $14 \%$ das vendas de águas engarrafadas. $\mathrm{Na}$ Europa e na Argentina, este percentual é ainda mais expressivo, representando cerca de $30 \%$ do mercado de águas minerais (EMBALAGEMMARCA, 2007). Embora no exterior tais produtos sejam enquadrados na categoria das águas minerais, no Brasil não recebem a mesma classificação, visto que pela legislação, para serem considerados água mineral, a matéria-prima não pode sofrer nenhum tipo de tratamento ou incorporação de aditivos. Assim, de acordo com a Agência Nacional de Vigilância Sanitária - Anvisa (BRASIL, 2007), recebem a denominação de "preparado líquido aromatizado". Apesar desta restrição, verifica-se que o mercado brasileiro acompanha a tendência externa, ganhando força em razão do lançamento destes produtos por uma grande multinacional do mercado de refrigerantes, fato que incentivou a comercialização do produto de outras marcas e com sabores variados. A tentativa de introdução desta categoria no País data desde o início da década atual, quando outros produtos, nacionais ou importados, foram lançados no mercado e fracassaram. O sabor e o preço, que não agradaram aos consumidores, aliados ao baixo investimento no marketing dos produtos, foram os principais fatores que contribuíram para este desempenho (ÁGUA \& VIDA, 2007a; EMBALAGEMMARCA, 2007). Assim, observa-se que as reais motivações para o seu consumo ainda são desconhecidas, com escassez de trabalhos científicos sobre o assunto, pelo fato do produto ser relativamente novo no mercado, estando ainda em fase de descobrimento e experimentação pelos consumidores.

O estudo do comportamento do consumidor é fundamental para entender o que o leva a consumir ou não um determinado produto e quais fatores estão envolvidos no processo de compra de um alimento. O sucesso ou fracasso de um produto depende de como o consumidor reage a ele (DAGEVOS, 2005; RODRIGUES, 2004; SOLOMON, 2002). Neste sentido, a pesquisa de mercado tem se mostrado uma ferramenta bastante útil para elucidar o comportamento dos consumidores de alimentos. Diversos trabalhos com abordagens distintas, aplicados em diferentes segmentos de mercado têm se dedicado a este tipo de pesquisa e contribuído para identificar as preferências, hábitos e costumes, o perfil socioeconômico, imagem de marca, intenções de compra e análise de participação do mercado, entre outras características do mercado (SAMARA; BARROS, 2002; SERRANO DOMÍNGUEZ, 2006; VERBEKE; VERMEIR; BRUNSO, 2007). Diante deste contexto, o presente trabalho teve por objetivo traçar o perfil dos consumidores de água aromatizada da cidade de Juiz de Fora/MG e avaliar o comportamento e as motivações que os levam a adquirir e a consumir os preparados líquidos aromatizados, comercialmente conhecidos como "águas aromatizadas".

\section{Material e métodos}

O universo de investigação deste estudo foi a cidade de Juiz de Fora, situada na Zona da Mata do Estado de Minas Gerais. Sua escolha baseou-se na proximidade com o Estado do Rio de Janeiro, considerada uma região de grande consumo do produto. A coleta dos dados foi realizada utilizando uma amostra intencional aleatória, estatisticamente significativa, composta de 303 consumidores, abordados em dois supermercados da região central da cidade, no período de 23 a 25 de junho de 2007. Para a definição do tamanho da amostra utilizou-se um nível de confiança de 95\% e uma margem de erro $\mathrm{E}=0,06$. Como não se conhecia o comportamento do mercado de água aromatizada na região, estimou-se uma variabilidade máxima de $50 \%$ (onde p e q estimados são iguais a 0,5 ). Assim, para a população do município analisado, o tamanho da amostra foi definido pela Equação 1 (TRIOLA, 2005).

$n=\frac{q p Z^{2}}{E^{2}}$

em que:

$$
\begin{aligned}
& \mathrm{n}=\text { tamanho da amostra; } \\
& \mathrm{Z}=1,96 \text { (abscissa da normal a um nível de confiança de } 95 \%) ; \\
& \mathrm{p}=0,5 \text { (variabilidade máxima estimada); } \\
& \mathrm{q}=1-\mathrm{p} ; \mathrm{e} \\
& \mathrm{E}=0,06 \text { (nível de precisão). }
\end{aligned}
$$

Para o levantamento dos dados utilizou-se uma pesquisa descritiva direta e estruturada (survey) por meio de amostragem aleatória simples, através da aplicação de questionários estruturados (MALHOTRA, 2001). A fim de evitar tendenciosidade nos resultados, optou-se por utilizar cartões circulares contendo todas as respostas para que o respondente apontasse a sua opção. A Figura 1 apresenta o resumo dos principais pontos abordados no questionário.

Os dados foram categorizados e analisados, de forma descritiva, utilizando o programa estatístico Statistical Package for the Social Sciences - SPSS for Windows versão 13.0. Realizou-se a correlação de Spearmam para verificar se há correlação entre o consumo de "água aromatizada" e as variáveis sexo, renda, escolaridade, idade e estado civil, assim como o interesse pelo produto e as variáveis opinião sobre o produto e motivação para o consumo.

\section{Resultados e discussão}

\subsection{Características demográficas dos consumidores}

Dos entrevistados, $65 \%$ eram do sexo feminino e 58,4\% eram solteiros. A faixa etária predominante dos consumidores situouse entre 20 e 30 anos (40,3\%), representativa do público-alvo do produto avaliado. A maioria dos indivíduos entrevistados possuía elevado grau de escolaridade, apresentando, no mínimo, ensino superior incompleto $(62,6 \%)$ e renda familiar entre 1 e 6 salários mínimos (52,8\%). Quanto à atividade profissional, 


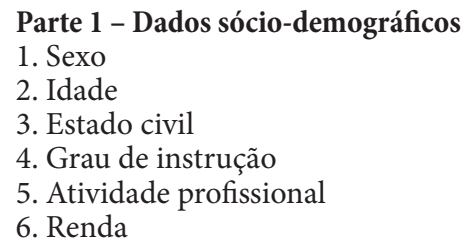

Parte 2 - Consumo de bebidas

7. Escolha da bebida baseada no prazer de consumo

8. Escolha da bebida para consumo imediato

9. Escolha da bebida para comsumo doméstico 10. Bebida apropriada para restrição calórica

Parte 3 - Consumo de "água aromatizada"

11. Consumo de água aromatizada

12. Interesse pelo produto

13. Opinião sobre o produto consumido

14. Local de consumo

15. Motivação para o consumo

16. Produto substituído pela água aromatizada

17. Momento adequado para o consumo

Figura 1. Questões abordadas no questionário aplicado aos consumidores.

$32,3 \%$ eram estudantes e $24,8 \%$ eram funcionários de empresa privada. Na Figura 2 está apresentado o resumo das características demográficas dos entrevistados.

As características demográficas dos entrevistados que afirmaram já ter experimentado o produto foram semelhantes a dos demais entrevistados, diferindo somente quanto à renda. Enquanto 37,4\% do total de entrevistados apresentaram renda entre 1 e 3 salários mínimos, somente 13,4\% dos consumidores do produto se enquadrou neste perfil. Apesar desta diferença, não foi observada correlação significativa $(p>0,05)$ entre a renda e o consumo da "água aromatizada". Este resultado também foi verificado entre o consumo de "água aromatizada" e as variáveis sexo, renda, escolaridade, idade e estado civil ( $p>0,05)$.

\subsection{Hábitos de consumo}

Na Figura 3 estão apresentadas as preferências dos consumidores na escolha de bebidas baseadas no prazer de consumo. O suco, o refrigerante e a água mineral natural destacaram-se entre as três mais consumidas. $\mathrm{O}$ suco de fruta foi indicado como a bebida preferida pelos entrevistados (34,3\%), enquanto o refrigerante foi o menos citado $(19,5 \%)$ entre as três bebidas acima. As águas aromatizadas foram as bebidas menos citadas em todos os níveis de consumo, coerente com o fato de serem recentes no mercado. Estes resultados refletem a crescente preocupação dos consumidores quanto à saúde, à forma física e à qualidade de vida, divulgados com maior frequência pela mídia e por estudos científicos, como relatados por Roodenburg, Leenen, (2007); Garber Jr., Hyatt, Starr Jr. (2003).

Em relação às bebidas adquiridas para consumo imediato (Figura 4), verificou-se que cerca de $67 \%$ dos entrevistados escolhiam a água mineral natural para saciar a sede. Entretanto, para o consumo doméstico, o suco $(42,9 \%)$ e o refrigerante

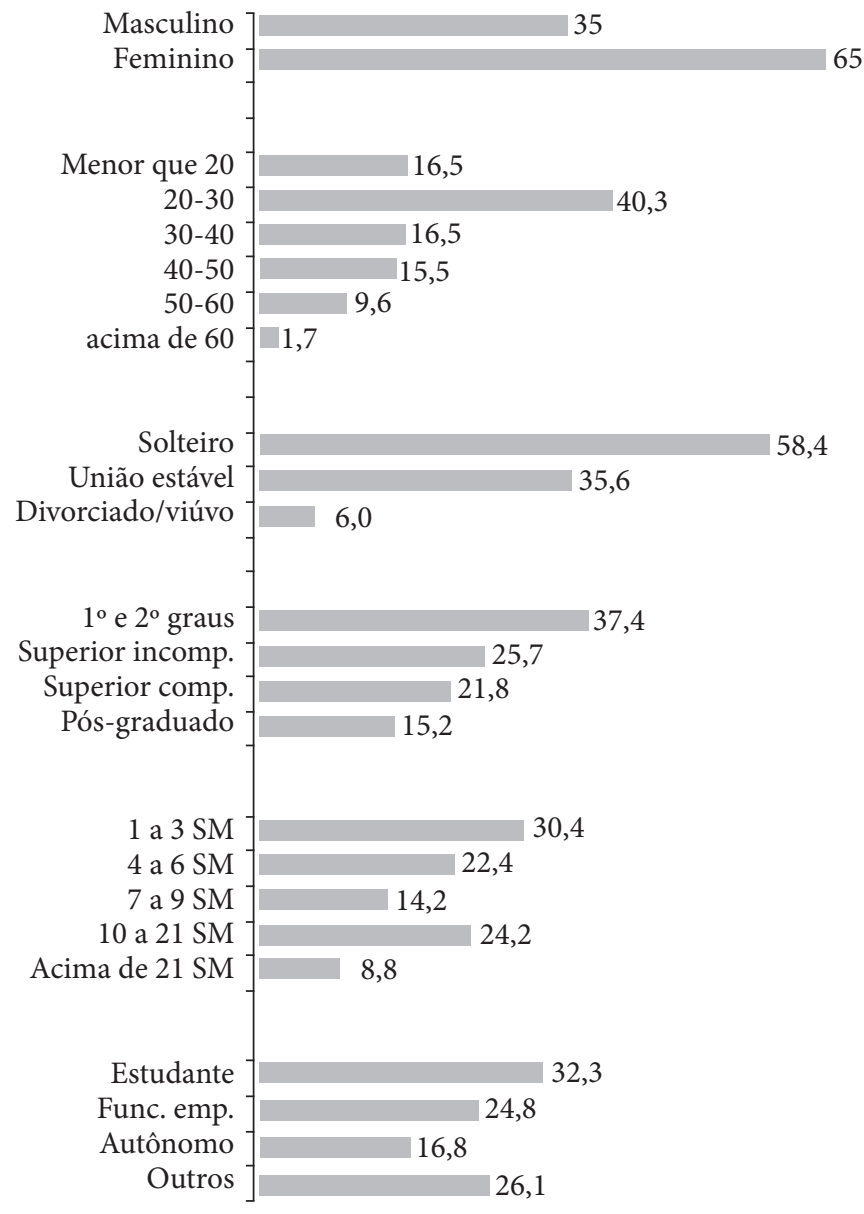

Figura 2. Frequência das características demográficas dos consumidores, expressos em porcentagem.

$(36,6 \%)$ foram os mais citados pelos respondentes. Estes valores sugerem a influência do momento de consumo e do contexto em que ele ocorre, visto que na primeira situação a escolha é individual e na segunda, a escolha poderia ser influenciada pela preferência dos membros da família, como observado em estudo realizado por Just, Heiman, Zilberman (2007).

Ao serem questionados sobre quais bebidas eram consumidas em situação de dieta com restrição calórica, verificou-se que a água mineral natural foi citada pelos consumidores como a bebida mais adequada para este fim $(47,2 \%)$, seguida do suco diet/light (30,7\%) e do refrigerante diet/light (16,5\%). A "água aromatizada" foi citada por $5,6 \%$ dos respondentes, sugerindo que para estes consumidores o apelo deste produto foi alcançado, uma vez que ele não contém calorias (Figura 5).

\subsection{Comportamento e motivações para o consumo da "água aromatizada"}

Quanto ao consumo do preparado líquido aromatizado (no questionário especificado como "água aromatizada”, a fim de facilitar a compreensão e o reconhecimento da bebida), verificou-se que 37,3\% dos entrevistados afirmaram que já consumiram ou consomem o produto. Este percentual é bastante 


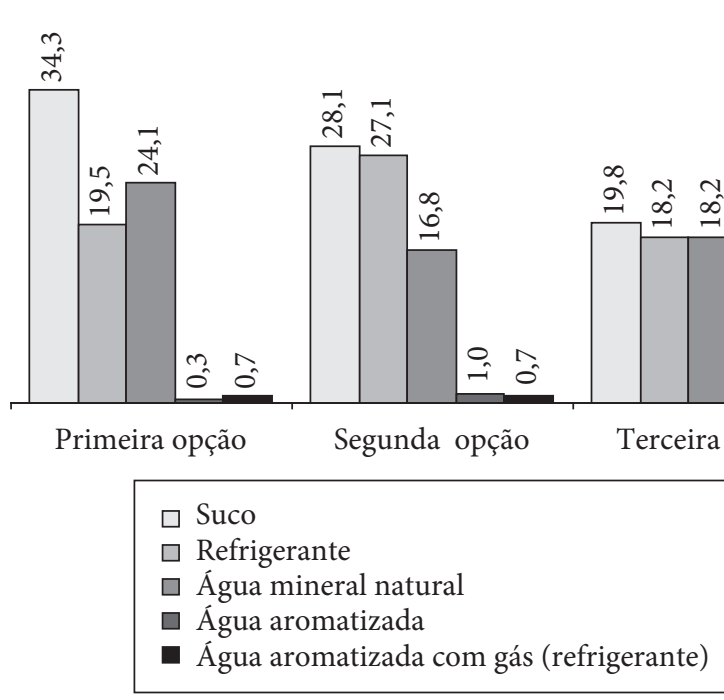

Figura 3. Preferência dos consumidores na escolha de bebidas baseada no prazer de consumo, expressa em porcentagem.

inferior ao encontrado pelo Instituto Qualibest (INSTITUTO QUALIBEST, 2007) numa pesquisa com questionários de autopreenchimento via web, no qual se verificou que $63 \%$ dos respondentes experimentaram o produto. Entretanto, deve-se ressaltar que nesta pesquisa foram realizadas 1287 entrevistas em âmbito nacional, com a aplicação favorecida pelo alcance da internet, sendo que a maior parte dos entrevistados residia nas cidades de São Paulo e Rio de Janeiro que, segundo Souza (SOLOMON, 2002), são as cidades brasileiras onde o produto foi inicialmente comercializado.

Dos entrevistados que afirmaram consumir a bebida, $58 \%$ disseram consumir uma marca existente no mercado e 3,6\% citaram outra marca. Observou-se, ainda, que dos $37 \%$ respondentes que afirmaram consumir o produto, $20,5 \%$ confundiram a "água aromatizada" com os refrigerantes de baixa gaseificação, visto que dois nomes comerciais de refrigerantes de baixa gaseificação foram mencionados. Esta confusão se deve em parte aos nomes sugestivos que remetem à água e ao aspecto visual deste produto (translúcido, sem corantes), conforme relatado pela revista Água \& Vida (ÁGUA \& VIDA, 2007b). Além disso, a disposição do produto nas prateleiras dos supermercados, localizadas próximas às das águas minerais, coopera para confundir o consumidor. Tal situação, gerada pelo rótulo e pela estratégia de marketing das empresas fabricantes de refrigerantes de baixa gaseificação, provocou protestos por parte da ABINAM, fato que colocou em evidência as "águas aromatizadas", contribuindo para alavancar este segmento.

O número limitado de marcas lembradas pelos entrevistados diferiu da pesquisa do Instituto Qualibest (2007), que reportou outras marcas além das mencionadas pelos respondentes nesta pesquisa, confirmando que tais produtos são mais consumidos nas metrópoles brasileiras. Entretanto, deve ser ressaltado que nos estabelecimentos onde a pesquisa foi realizada, apenas duas marcas de água aromatizada eram comercializadas. O grande percentual de entrevistados $(70,2 \%)$ que mencionaram nunca ter consumido o produto por ignorarem sua existência demonstrou

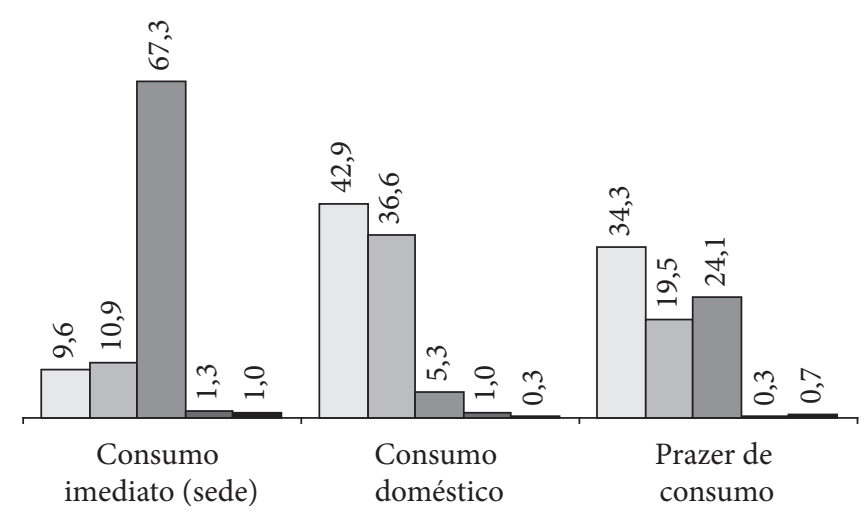

$$
\begin{aligned}
& \square \text { Suco } \\
& \square \text { Refrigerante } \\
& \square \text { Água mineral natural } \\
& \square \text { Água aromatizada } \\
& \square \text { Água aromatizada com gás (refrigerante) }
\end{aligned}
$$

Figura 4. Preferência dos consumidores, expressa em porcentagem, na escolha de bebidas em diferentes situações de consumo: consumo imediato, consumo doméstico e pelo prazer de consumo.

falhas na divulgação destes produtos por parte das empresas, nos mercados ou na mídia local, como verificado. Segundo a revista Água \& Vida (2007b), este fator é responsável por 11\% do fracasso das "novas águas" (caracterizadas pela adição de vitaminas, essências, adoçantes, dentre outros) lançadas no mercado norte-americano.

Neste levantamento, o preço não foi um fator determinante para desestimular a aquisição do produto pelos consumidores, uma vez que apenas $2,1 \%$ disseram que não consumiram o produto em razão do seu preço. A percepção negativa do consumidor perante o produto influenciou a sua intenção de compra, uma vez que $14,1 \%$ afirmaram não tê-lo consumido porque não gostam do produto. Este fato pode ser confirmado uma vez que $59,7 \%$ dos entrevistados que não experimentaram tinham pouco ou nenhum interesse pelo produto.

Para avaliar as motivações quanto ao consumo da água aromatizada, excluíram-se os valores referentes aos indivíduos que confundiram o produto com os refrigerantes de baixa gaseificação. Desta forma, observou-se que a maioria dos entrevistados que experimentou a "água aromatizada" mencionou o fator novidade $(64,3 \%)$ e o sabor $(21,4 \%)$ como as principais motivações para o seu consumo. Estes resultados indicam que, apesar do marketing do produto se basear na questão da saúde (produtos com zero caloria e, em alguns casos, enriquecidos com vitaminas e/ou fibras) aliada ao sabor (ÁGUA \& VIDA, 2007a), na prática o principal fator que impulsiona os consumidores a adquirirem e a experimentarem a bebida baseia-se na novidade, na curiosidade que ela desperta nas pessoas. Além disso, o produto agradou uma parcela considerável dos entrevistados, visto que 55,1\% gostaram do produto, apesar de $28,1 \%$ apresentaram opinião contrária.

Apesar de estes dados indicarem boas perspectivas quanto à comercialização do produto, verificou-se que elas esbarram no 
baixo interesse demonstrado pelos consumidores da bebida, em que $29,2 \%$ destes apresentaram interesse moderado ou grande pelo produto, opinião compartilhada com os entrevistados que nunca consumiram a "água aromatizada" (21,0\%), conforme mostrado na Figura 6.

Observou-se relação positiva entre o interesse do consumidor pelo produto e sua motivação para consumi-lo. Também houve relação entre o grau de interesse do entrevistado e a sua opinião sobre o produto. Estes resultados foram confirmados pela correlação significativa entre as variáveis ( $\mathrm{r}$ de Spearmam), ao nível de $5 \%$ de probabilidade. Tal fato demonstra a necessidade de investimentos e justifica as ações das indústrias em realizar campanhas de marketing com o objetivo de motivar o consumidor por meio de apelos que induzam à satisfação de suas necessidades e consequentemente criar ou modificar a sua opinião, para um conceito positivo do produto.

Dos consumidores que gostaram do produto, $42,9 \%$ demonstraram interesse pela bebida, enquanto $34,7 \%$ apresentaram pouco ou nenhum interesse (Figura 7).

Muitos dos consumidores que foram motivados a experimentar a "água aromatizada" pelo fator novidade apenas 15,5\%

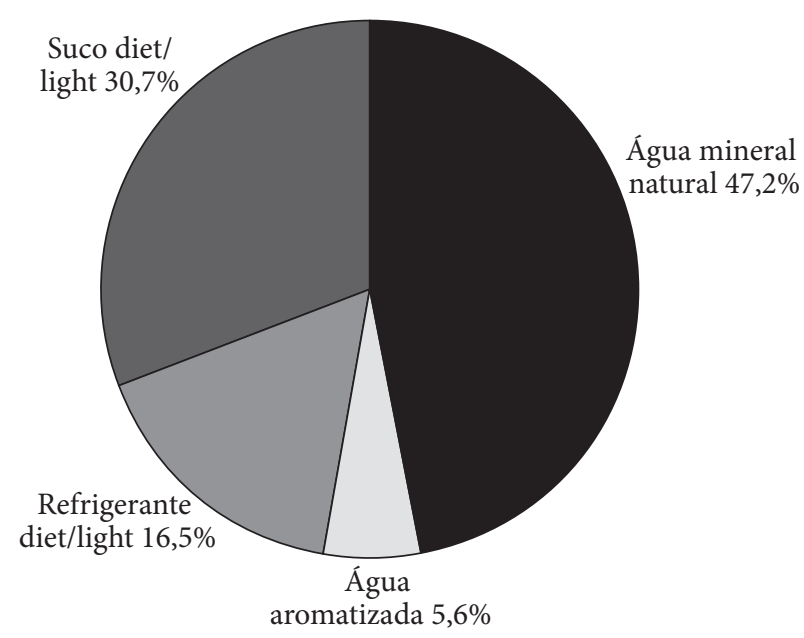

Figura 5. Preferência de bebidas consumidas em situação de dieta com restrição calórica.

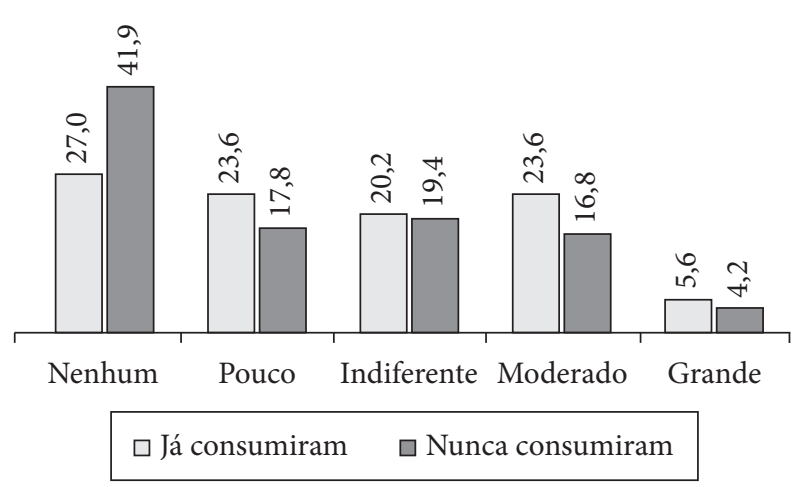

Figura 6. Grau de interesse dos entrevistados pelo produto (valores percentuais). apresentaram interesse pelo produto. Desta forma, uma parcela considerável demonstrou baixo ou nenhum interesse pela bebida $(60,3 \%)$, comportamento que pode estar associado tanto ao fato do consumidor desgostar do produto ao experimentá-lo ou, então, por não ter interesse em adquiri-lo novamente, apesar de ter gostado dele. Outros foram motivados pelo sabor, dos quais 50,0\% demonstraram interesse pela bebida. Entretanto, $38,9 \%$ destes consumidores apresentaram baixo interesse pelo produto, sugerindo que suas características não são fortes o suficiente para levá-los a recompra ou que a sua divulgação tem se mostrado ineficiente (Figura 8). O grau de interesse dos entrevistados motivados pela preocupação com a saúde, com a forma física ou por outro fator não foi descrito, uma vez que havia apenas cinco respondentes por categoria, e inferências poderiam ser equivocadas.

Em relação ao local e ao momento adequados ao consumo, $34,8 \%$ mencionaram o domicílio e $17,9 \%$ lanchonetes como os locais mais apropriados e $63 \%$ dos entrevistados afirmaram não existir um momento adequado para o consumo. Este

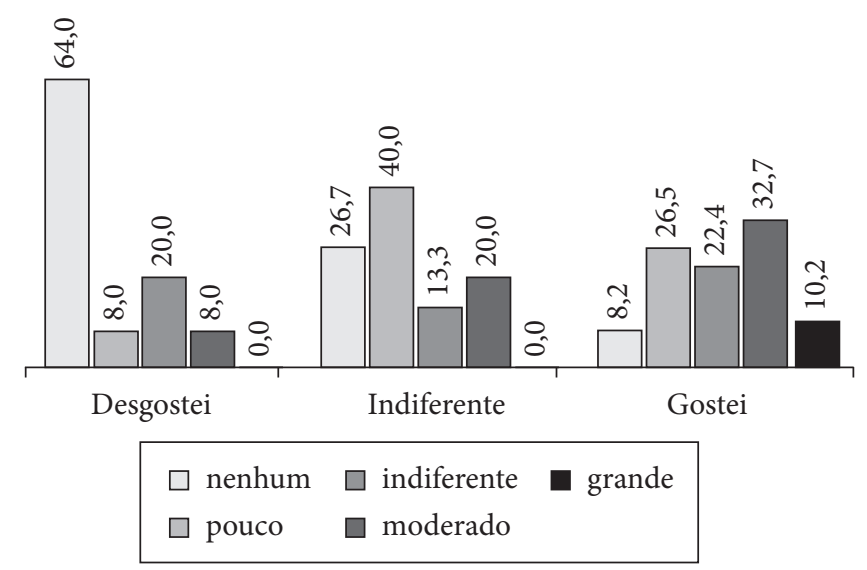

Figura 7. Grau de interesse em função da opinião dos consumidores da bebida (valores percentuais).

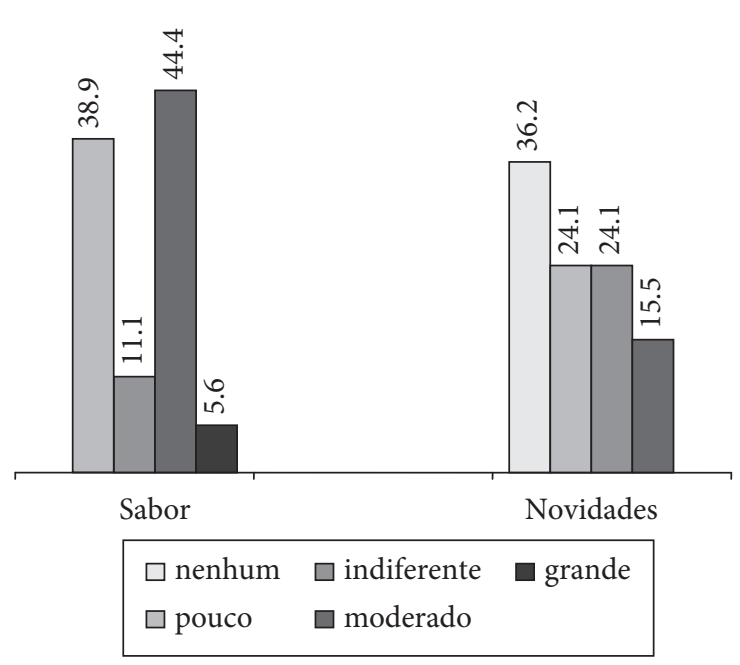

Figura 8. Grau de interesse em função da motivação para o consumo da bebida (valores percentuais). 
comportamento mostra que não há restrição quanto ao local e ao momento de consumo deste produto, o qual poderia ser comercializado em diferentes estabelecimentos, tanto para consumo imediato quanto para consumo doméstico.

Dentre os produtos que poderiam ser eventualmente substituídos pela “água aromatizada” (água mineral natural, água mineral com gás, refrigerante, chá gelado e bebida isotônica), o refrigerante foi citado por $44,9 \%$ dos consumidores. Este resultado reflete a atual e crescente necessidade dos consumidores em adquirir e consumir alimentos saudáveis, visto que o refrigerante se destacava como a bebida menos benéfica à saúde. Os produtos que constavam neste item foram selecionados com base no seu principal apelo, a hidratação, um fator também explorado pela "água aromatizada", sendo por este motivo, considerados como seus possíveis concorrentes.

\section{Conclusões}

Os resultados obtidos indicaram que uma parcela considerável dos entrevistados que afirmou já ter consumido a "água aromatizada" foi motivada principalmente pelo caráter novidade exibido pelo referido produto. Observou-se, ainda, que parte destes consumidores confundiu o produto com os recémlançados refrigerantes de baixa gaseificação, demonstrando que as "águas aromatizadas" ainda não conseguiram se posicionar adequadamente no mercado.

Diante destes resultados, verifica-se que os preparados líquidos aromatizados surgem como alternativa inovadora para a substituição de diversos produtos, principalmente refrigerantes, numa tentativa de suprir a atual e crescente necessidade dos consumidores em adquirir e consumir alimentos benéficos à saúde e que contribuam para uma melhor qualidade de vida. Entretanto, verifica-se que a divulgação destes produtos é ineficiente na cidade avaliada e que suas características não são atrativas a uma grande parcela dos consumidores, necessitando de atenção especial, a fim de que o consumo não se baseie apenas no modismo, um fator que é passageiro e insuficiente para manter qualquer produto no mercado.

\section{Agradecimentos}

À Capes e ao CNPq pelo suporte financeiro. Aos estabelecimentos comerciais onde foi realizada a pesquisa.

\section{Referências bibliográficas}

ÁGUAS aromatizadas crescem como alternativa a refrigerantes. ÁGUA \& VIDA, n. 45, p. 10-13, 2007a.

SAÚDE e energia são as tendências dominantes no desenvolvimento de novos produtos na indústria mundial de bebida. ÁGUA \& VIDA, n. 46 , p. $6-10,2007 b$.
BRASIL. Resolução RDC 273, de 22 de setembro de 2005. Regulamento técnico para misturas para o preparo de alimentos e alimentos prontos para o consumo. Diário Oficial da República Federativa do Brasil, Brasília, 22 de Setembro de 2005. Disponível em: <http://elegis.anvisa.gov.br/leisref/public/showAct.php?id=18832 \&word=>. Acesso em: 9 de Maio de 2007.

DAGEVOS, H. Consumers as four-faced creatures: looking at food comsumption from the perspective of contemporary consumers. Appetite, v. 45, n. 1, p. 32-39, 2005.

INDÚSTRIA de água mineral cresce com novos hábitos do consumidor. ECONOMIA \& DESENVOLVIMENTO, n. 21, p. 20-24, 2005. Disponível em: <http://www.seplan.go.gov.br/rev/revista21/cap06. pdf $>$. Acesso em: 9 de Maio de 2007.

AO sabor das águas: crescem as opções diferenciadas da mais natural das bebidas. EMBALAGEMMARCA n. 91, p. 38-41, 2007.

GARBER Jr., L. L.; HYATT, E. M.; STARR Jr., R. G. Measuring consumer response to food products. Food Quality and Preference, v. 14, n. 1, p. 3-15, 2003.

INSTITUTO QUALIBEST. Água aromatizada pode tirar mercado de refrigerante. Disponível em: <http://www2.uol.com.br/canaexecutivo/ notas07/230420078.htm>. Acesso em: 15 de Junho de 2007.

JUST, D. R.; HEIMAN, A.; ZILBERMAN, D. The interaction of religion and family member's influence on food decisions. Food Quality and Preference, v. 18, n. 5, p. 786-794, 2007.

MALHOTRA, N. Pesquisa de Marketing: uma orientação aplicada. Porto Alegre: Bookman, 2001. 720 p.

ROODENBURG, A. J. C.; LEENEN, R. How food composition databases can encourage innovation in the food industry. Trends in Food Science \& Technology, v. 18, n. 8, p. 445-449, 2007.

RODRIGUES, M. A.; JUPI, V. S. O comportamento do consumidor: fatores que influenciam em sua decisão de compra. Revista de Administração Nobel, n. 3, p. 59-70, 2004.

SAMARA, B. S.; BARROS, J. C. Pesquisa de Marketing: conceitos e metodologia. São Paulo: Pearson Prentice Hall, 2002. 260 p.

SERRANO DOMÍNGUEZ, C. Retailing establishments: a competitive analysis of commercial formats from the consumer's profile and perceptions. Journal of Retailing and Consumer Services, 2006. In Press.

SOLOMON, M. R. Comportamento do consumidor: comprando, possuindo e sendo. Porto Alegre: Bookman, 2002. 445 p.

SOUZA, C. H2OH! surpreende o mercado e Coca-Cola lança concorrente. O Globo On Line - Economia. Disponível em: <http://oglobo. globo.com/economia/mat/2007/05/18/295809667.asp>. Acesso em: 12 de Junho de 2007.

VERBEKE, W.; VERMEIR, I.; BRUNSO, K. Consumer evaluation of fish quality as basis for fish market segmentation. Food Quality and Preference, v. 18, n. 4, p. 651-661, 2007.

TRIOLA, M. F. Introdução à estatística. Rio de Janeiro: LCT, 2005.

WANSINK, B. Helping consumers eat less. Food Technology, v. 61, n. 5, p. 34-38, 2007.

WEINBERG, M. O admirável mundo das águas. Veja, n. 2010, p. $110-111,2007$. 